\title{
RNA stabilization by a poly(A) tail 3 ' -end binding pocket and other modes of poly(A)-RNA interaction
}

\author{
Seyed-Fakhreddin Torabi ${ }^{1,2}$, Anand T. Vaidya ${ }^{1,2,3}$, Kazimierz T. Tycowski, ${ }^{1,2}$, Suzanne J. DeGregorio ${ }^{1,2}$, \\ Jimin Wang', Mei-Di Shu1,2, Thomas A. Steitz ${ }^{1,2 *}$, Joan A. Steitz ${ }^{1,2} \uparrow$ \\ ${ }^{1}$ Department of Molecular Biophysics and Biochemistry, Yale University School of Medicine, New Haven, CT 06536, USA. ${ }^{2}$ Howard Hughes Medical Institute, Yale \\ University School of Medicine, New Haven, CT 06536, USA. ${ }^{3}$ TIFR Centre for Interdisciplinary Sciences, Tata Institute of Fundamental Research, Hyderabad \\ 500046, India.
}

*Deceased.

†Corresponding author. Email: joan.steitz@yale.edu

Poly(A) tail addition to the $3^{\prime}$ end of a wide range of RNAs is a highly conserved modification that plays a central role in cellular RNA function. Elements for nuclear expression (ENEs) are cis-acting RNA elements that stabilize poly(A) tails by sequestering them in RNA triplex structures. A 2.89- $\AA$ resolution crystal structure of a double ENE from a rice hAT transposon mRNA complexed with poly $(A)_{28}$ reveals multiple modes of interaction with poly(A), including major-groove triple helices, extended minor-groove interactions with RNA double helices, a quintuple-base motif that transitions poly $(A)$ from minor-groove associations to major-groove triple helices, and a poly(A) $3^{\prime}$-end binding pocket. Our findings both expand the repertoire of motifs involved in long-range RNA interactions and provide insights into how polyadenylation can protect an RNA's extreme $3^{\prime}$ end.

Cis-acting RNA elements play crucial roles in stabilizing polyadenylated RNAs, which include both mRNAs and long noncoding RNAs (lncRNA) (1-5). One cis-acting RNA element conferring RNA stabilization is the element for nuclear expression (ENE), which contains a U-rich internal loop (URIL) flanked by short double helices. ENEs reside mostly in $3^{\prime}$ untranslated regions (UTRs) of mRNAs or in the $3^{\prime}$ proximal regions of lncRNAs (6-9). The ENE was first identified in polyadenylated nuclear (PAN) lncRNA that is expressed by oncogenic Kaposi's sarcoma-associated herpesvirus (KSHV) (6). The PAN ENE acts by sequestration of the poly(A) tail via formation of a triplex composed of five $\mathrm{U}-\mathrm{A} \cdot \mathrm{U}$ triples that protect the RNA from rapid deadenylation-dependent decay (10-12). This leads to the accumulation of PAN RNA to astonishingly high levels (up to $\sim 500,000$ copies per nucleus) in KSHV-infected cells $(11,13)$.

Discovery of the PAN ENE led to the bioinformatic prediction of numerous ENEs in the genomes of other viruses, as well as in fungi and plants $(9,14)$. Moreover, ENEs were identified in two abundant vertebrate lncRNAs, i.e. human metastasis-associated lung adenocarcinoma transcript 1 (MALAT1) and multiple endocrine neoplasia $\beta$ (MEN $\beta$ ) (7, 8). Abnormal up-regulation and accumulation of MALAT1 reported in various human cancers require the ENE at the $3^{\prime}$ end (15-17).
High-resolution crystal structures of ENE triplexes from KSHV PAN (11) and human MALAT1 RNAs (17) revealed that they both contain stacked major-groove triples involving the poly(A) tail (PAN RNA) or 3' -A-rich tract (MALAT1) (fig. S1). In each case, the triplex is fortified by adjacent Aminor interactions (18) with double-stranded RNA. The PAN ENE sequesters only five nucleotides of the poly(A) tail within a triplex, leaving its $3^{\prime}$ end exposed downstream of the triplex $(11,17)$. In contrast, MALAT1 terminates with an A-rich tract, generated by RNase P processing, and harbors an ENE URIL interrupted by $\mathrm{C}$ and $\mathrm{G}$ nucleotides, which interact with complementary nucleotides in the A-rich tract, locking its register to form a blunt-ended triplex (fig. S1B) (17). Thereby, the MALAT1 triplex inhibits the rapid nuclear deadenylation-dependent decay pathway more effectively than PAN RNA, which slows only the initial phase of decay $(10,12,17)$.

Recently, double ENEs (dENEs), containing two URILs separated by a predicted double-helical region (Fig. 1A and fig. S2), were found in transposable element (TE) mRNAs, mostly in plants and fungi (9). Interestingly, unlike PAN and MALAT1 ENEs, all dENEs possess three highly conserved adenosines (the adenosine triad) (cyan in fig. S2). In the predicted secondary structure of dENEs, two of the adenosines lie in the lower URIL, while the third is bulged 
from the lower stem. In addition, dENEs exhibit a striking pyrimidine/purine $(\mathrm{Y} / \mathrm{R})$ bias in the composition of the URIL-flanking stems that are not expected to interact with poly(A), based on the crystal structures of the PAN and MALAT1 triplexes $(9,19)$ (figs. S1 and S2).

To gain insight into the molecular architecture and function of dENEs, we determined the crystal structure of the dENE from rice TWIFB1, a hAT DNA transposon, complexed with poly $(\mathrm{A})_{28}$. The TWIFB1 dENE is located $35 \mathrm{nt}$ upstream of the poly(A) tail in the $3^{\prime}$ UTR of the transposase mRNA. The $2.89-\AA \AA$ resolution structure reveals several different modes of interaction between the dENE and poly(A), including 1) the expected major-groove triplexes, 2) a previously unnamed class of minor-groove interactions between poly(A) and double helices, 3) quintuple-base motifs that transition poly(A) from minor-groove interactions to major-groove triplexes, and 4) a novel poly(A) 3 '-end binding pocket. We demonstrated the physiological significance of all these motifs for RNA stabilization and uncovered their conservation in many other RNAs.

\section{Crystallization and structure determination of a dENE+poly $(\mathbf{A})_{28}$ complex}

Electrophoretic mobility shift assays (EMSAs) demonstrated that the dENE binds poly(A) in trans and that binding affinity increases with poly(A) length (supplementary text and Fig. 1C and fig. S3A). Surprisingly, poly(A) binding was lost when the URIL-flanking Y/R biased stems, not predicted to engage in poly(A) interactions, were strand-swapped (fig. S3B). This suggested that interactions of the poly(A) with the dENE extend into the middle and upper stems (Fig. 1A). After testing more than 40 different variants, a modified dENE construct was eventually obtained (Xtal, Fig. 1B), which contains the dENE core (green in Fig. 1, A and B), binds poly (A), and yields crystals that diffract well (supplementary text, Fig. 1, A to C, and fig. S4). As judged by the cell-based intronless $\beta$-globin $(\beta \Delta 1,2)$ reporter assay, the Xtal dENE is active in RNA stabilization (supplementary text and Fig. 1D). The X-ray structure of the 86-nt Xtal dENE bound to a 28 -mer poly(A) was determined at $2.89-\AA$ resolution with $R_{\text {work }}$ and $R_{\text {free }}$ of 0.18 and 0.22 , respectively (fig. S5 and table S1).

\section{Overall architecture of the $\operatorname{dENE}+\operatorname{poly}(\mathrm{A})_{28}$ complex}

Similar to ENEs from PAN RNA and MALAT1 $(11,17)$, the dENE forms major-groove RNA triplexes with poly $(\mathrm{A})_{28}$ (fig. S6). However, the structure reveals several unanticipated features. One is that poly(A) interacts with the upper dENE domain and then the lower dENE domain in a $5^{\prime}$ to $3^{\prime}$ direction (Fig. 1, E and F, and fig. S7), which is opposite to the directionality predicted (fig. S2B) based on structural homology with the PAN and MALAT1 ENEs $(9,19)$. Between the two triple-stranded features, electron density is missing for five adenylates from the poly $(\mathrm{A})_{28}$ and they do not appear in the model (Fig. 1E). Presumably, this region is conformationally disordered as it appears that intact poly(A) RNAs are recovered from the crystals (fig. S8).

A second unexpected feature is that multiple consecutive adenosines associate with the minor groove of the upper stem to form non-canonical A-minor interactions (Fig. 2, A to C, and figs. S9 and S10). In contrast to the few classical A-minor interactions observed adjacent to the PAN (11) and MALAT1 (17) triplexes, which form by insertion of the minor-groove edge of adenines into the minor groove of an RNA stem (18), these minor-groove interactions involve the Watson-Crick edge or both the Watson-Crick and Hoogsteen edges of adenines (supplementary text). Therefore, we call them $\mathrm{WC} / \mathrm{H} \mathrm{A}$-minor interactions. While the $\mathrm{N} 1$ and $\mathrm{N} 6$ atoms of the poly(A) A5, A6 and A8 hydrogen bond to dENE residues A82, G6 and U80, respectively, within the minor groove of the upper stem to form base triple interactions, A7 is twisted with respect to the upper stem and associates with two adjacent base pairs through formation of a quintuple-nucleotide interaction involving its $\mathrm{N} 1, \mathrm{~N} 6$ and $\mathrm{N} 7$ (Fig. 2, B and C, and fig. S11A). After forming several WC/H A-minor interactions, the poly(A) makes a transition to an extended $\mathrm{U}-\mathrm{A} \cdot \mathrm{U}$ major-groove triplex through another quintuple-base interaction, which involves two poly(A) nucleotides (A9 and A10) and three dENE nucleotides (U9 and the C79-G8 base pair) (Fig. 2, D to F, and figs. S9 and S11B). The structure of the upper dENE domain and that of its counterpart in the lower domain (i.e., the quintuple-base transition motif and major-groove triplex) are so similar to each other that they superimpose with a root mean square deviation (RMSD) of $0.8 \AA$ (fig. S12).

\section{A poly $(A) 3$ ' -end binding pocket composed solely of RNA facilitates formation of a blunt-ended triple helix}

The crystal structure further reveals that the lower dENE domain contains a novel structural feature transitioning to the lower stem, which we call a "pocket motif". This motif is absent from the upper dENE domain (figs. S9 and S10) and was not seen in any previous ENE crystal structure $(11,17)$. The pocket resides at the border between the lower URIL and the lower stem of the dENE; it is formed through the stacking of the bases of A30, A31 and A56 (cyan in Fig. 3 and fig. S13) within the major groove of the lower stem directly abutting the URIL. The base of A56 is splayed apart from its two adjacent nucleotides in the primary sequence, U55 and C57, and is stacked between A30 and A31 (Fig. 3A and fig. S14). In addition, the 2 '-OH group and the $\mathrm{O}^{\prime}$ ' oxygen of A56 ribose are hydrogen bonded to $\mathrm{N} 6$ of A30 and $\mathrm{N} 6$ of A31, respectively, and N1 of A31 is hydrogen bonded to the C57-G35 pair (Fig. 3, A and B, and figs. S2 and S14). To form 
such unprecedented architecture three nucleotides of the pocket motif, A31, C32 and A56, adopt a C2'-endo sugar pucker (fig. S14). Moreover, C32 adopts a syn conformation and flips its base out into solution, which allows positioning of G33 to form the C59-G33 base pair (Fig. 3, A and B). Collectively, these rare structural features bend the RNA backbone of the pocket motif into the shape of the letter $\mathrm{Z}$ (Fig. $3 \mathrm{~A})$. By forming a $\mathrm{U}-\mathrm{A} \cdot \mathrm{U}$ triple, the $3^{\prime}$-most adenosine of poly(A) becomes poised to form a hydrogen bond between its 3 '-OH group and the G33 phosphate within the backbone of the pocket (Fig. 3 and fig. S14B).

The pocket motif is one feature distinguishing the TWIFB1 dENE from previous ENE structures. As shown in surface representation, in the PAN and MALAT1 triplexes the poly(A) tail or the A-rich tract follows a path that points toward an accessible space, i.e., the minor groove of the flanking stem (Fig. 4A and fig. S15). Thereby, the $3^{\prime}$ end of poly(A) could be easily extended. Yet, MALAT1 forms a $3^{\prime}$ blunt ended triplex because the register of its A-rich tract is fixed (fig. S6C) (17). Similar to the PAN and MALAT1 ENEs, the TWIFB1 upper dENE domain does not recognize the $3 '$ ' most adenosine of the poly(A). Indeed, a nucleotide (A15) emerges from the major-groove triplex (Fig. 4A). In contrast, the poly(A) encounters a blockade - the pocket motif - at its $3^{\prime}$ end in the TWIFB1 lower dENE domain, such that the minor-groove pathway in the flanking stem is not open (Fig. $4 \mathrm{~A}$ and fig. S15). We were able to superimpose the majorgroove triplexes and flanking 3-bp stems from the TWIFB1 upper dENE domain on those of the PAN and MALAT1 ENEs (RMSD = 1.1 and $1.2 \AA$, respectively) (Fig. 4B). None of these three ENEs exhibits structural constraints that should prevent emergence of a $3^{\prime}$ poly(A) overhang. In contrast, superposition of the upper and lower major-groove triplexes from the TWIFB1 dENE clearly shows that insertion of the adenosine-triad bases into the major groove of the 3-bp stem flanking the lower triplex results in movement of the closing base pair of the lower domain compared to that of the upper domain ( $10 \AA$ ) (Fig. 4B). The exit path of poly(A) is blocked by creation of a pocket for the poly(A) $3^{\prime}$ end. Therefore, the unique architecture of the pocket sequesters the poly(A) $3^{\prime}$ end and facilitates the formation of a $3^{\prime}-$ blunt ended triplex.

We used quantitative EMSAs to determine the functional importance of the pocket in poly(A) binding by the dENE. First, we compared the poly $(\mathrm{A})_{28}$-binding affinity of the wild-type dENE and pocket-deleted ( $\triangle$ pocket) mutant (fig. S16). The $\triangle$ pocket mutant showed an $\sim 4$-fold increase in its apparent dissociation constant $\left(K_{\mathrm{d}}\right)$ for poly $(\mathrm{A})_{28}$ (fig. S16). Furthermore, we examined the effect of creating a steric clash between the dENE G33 phosphate and a bulky group (e.g., a 3 '-overhanging nucleotide) appended to the 3 ' end of poly(A) ${ }_{28}$. Such constructs exhibited 1) lower poly(A) bind- ing affinity, and 2) significant smear formation below the complex band (figs. S16 and S17). Compensatory mutations in the dENE or poly(A), which - based on the structure should abolish the introduced steric clash, enhanced poly(A) binding affinity and resolved smear formation (supplementary text and figs. S16 and S17). Finally, we found that substituting the $3^{\prime}-\mathrm{OH}$ of poly(A) with a $2^{\prime}, 3^{\prime}$-cyclic phosphate resulted in an $\sim 2$-fold decrease in $K_{\mathrm{d}}$ (fig. S18). Thus, our biochemical data confirm our crystallographic observations that the $3^{\prime}$-most adenosine of poly(A) is tightly bound in the pocket with its $3^{\prime}-\mathrm{OH}$ group contributing importantly.

To obtain more insights into the function of the pocket in poly(A) 3'-end protection, we performed in vitro deadenylation assays $(11,12)$ on substrates containing either the wild-type or the $\triangle$ pocket dENE extended with poly $(\mathrm{A})_{72}$. While the wild-type dENE protects the substrate from decay, mutational deletion of the pocket renders the RNA susceptible to degradation (Fig. 4D). To show that the observed degradation represents deadenylation, we used a double U to $\mathrm{C}$ mutant dENE (M26 in fig. S17) terminating with poly $(\mathrm{A})_{69} \mathrm{G}(\mathrm{A})_{22}$, which is expected to lock the poly(A) register by forming a $\mathrm{C}-\mathrm{G} \cdot \mathrm{C}^{+}$triple (Fig. $4 \mathrm{C}$ ). We observed rapid initial substrate shortening and then accumulation of a product whose length is consistent with the size of the wildtype dENE-poly(A) $)_{72}$ (Fig. 4D and supplementary text). Together, these results demonstrate the importance of the pocket in formation of a 3 '-blunt ended triplex structure through a steric mechanism, which inhibits deadenylation in vitro.

\section{Significance of dENE+poly(A) structural features in RNA stabilization}

Cellular accumulation of the $\beta \Delta 1,2$ reporter transcript has previously been used to assess the in vivo functionality of ENEs as cis-acting RNA stabilization elements $(6,7,9,14)$. To evaluate the functional significance of the structural features of the dENE+poly $(\mathrm{A})_{28}$ complex, a series of $\beta \Delta 1,2$ reporters was generated by inserting either wild-type or mutant dENE variants into the 3 ' UTR and assaying $\beta$ globin transcript accumulation in human HEK293T cells (Fig. 5). The data show that, overall, disruption of any of the identified structural features (Fig. 5B) reduces the RNA stabilization activity of the dENE (Fig. 5C). We tested identical mutations in features common to the two dENE domains (e.g., M1 versus M3, M2 versus M4, etc.) and observed that mutations in the lower domain are better tolerated. This observation is consistent with the presence of the poly(A) $3^{\prime}$-end binding pocket in the lower dENE domain, which may partially compensate for mutations disrupting the major-groove triplex of the lower domain (supplementary text). Mutations in any of the three residues involved in formation of the quintuple-base transition motif (M1, M5 and M7 in 
the upper, and M3, M6 and M8 in the lower dENE domain) reduce the dENE stabilization activity to an extent comparable to mutations in the major-groove triplexes (M16 and M19 in the upper, and M17 and M20 in the lower dENE domain). More interestingly, mutations that disrupt only the poly(A) 3 '-end binding pocket (M10 to M13), despite leaving other poly(A)-dENE interactions unperturbed, reduce the accumulation of $\beta$-globin mRNA by $\sim 50 \%$. Thus, the pocket is important for the stabilization activity of the dENE. In addition, our structure reveals molecular interactions that support the frequent occurrence of a non-canonical $\mathrm{G} \cdot \mathrm{A}$ pair as the closing base pair of upper dENE domains (fig. S2). The reason is that the adenine of the G74•A14 base pair provides a platform for stacking interactions with the adenosine in the last major-groove triple of the upper domain (supplementary text and fig. S19). Finally, we evaluated the effect of $\mathrm{WC} / \mathrm{H}$ A-minor interactions in the upper dENE domain by mutating their receptor base pairs (fig. S20). Mutations that disrupted $\mathrm{Y} / \mathrm{R}$ bias reduced accumulation of the reporter transcript by $\sim 20 \%$ to $30 \%$, indicating that $\mathrm{WC} / \mathrm{H}$ A-minor interactions contribute to stabilization activity (supplementary text). As expected, mutations in the portion of the middle stem that is not involved in any interaction with poly(A) have minimal effects (M14: < 20\%; M15: no effect) on dENE stabilization activity.

Functional significance of blunt-ended triplexes, formed through fixing the register of downstream A-rich tracts, has been studied before $(7,17)$. For example, it was shown that addition of 3 ' overhangs reduces MALAT1 ENE stabilization activity (7). We tested stabilization activity of the TWIFB1 dENE when inserted upstream of a 54- or 72-mer poly(A) tract using the $\beta \Delta 1,2$ reporter assay. Indeed, the dENE exhibits robust stabilization activity that resembles the activity of a blunt-ended triplex (MALAT1 ENE) rather than that of those with a $3^{\prime}$ overhang ( $\triangle$ pocket dENE or PAN ENE) (supplementary text and fig. S21). We conclude that formation of a pocket-mediated blunt-ended triple helix counteracts RNA decay in vivo.

\section{WC/H A-minor interactions and the quintuple-base transition motif are common to other RNAs}

The WC/H A-minor and quintuple-base transition motifs observed in the TWIFB1 dENE+ $\operatorname{poly}(\mathrm{A})_{28}$ structure are not unique. Sequence alignment argues that such motifs also appear in many single-domain (fig. S22) and other doubledomain ENEs (fig. S2A). We searched ribosomal RNA and small RNA structures in the Protein Data Bank (PDB) and found several equivalent $\mathrm{WC} / \mathrm{H}$ A-minor and quintuple-base transition motifs. For example, the S-adenosylhomocysteine (SAH) riboswitch possesses three consecutive adenosines that form a WC/H A-minor motif (20) superimposable on the $\mathrm{A} 7, \mathrm{~A} 8$ and $\mathrm{A} 9 \mathrm{WC} / \mathrm{H}$ A-minor motif of the
dENE+poly $(\mathrm{A})_{28}$ complex with an RMSD $=0.9 \AA$ (Fig. 6A and fig. S23A). The quintuple-base transition motif is also found in other RNAs (fig. S24), such as the guide RNA transactivating CRISPR RNA from the Campylobacter jejuni CRISPR-Cas9 system (Cas9 trans-activating crRNA) (21), where this motif connects a WC/H A-minor triple to a $\mathrm{G}$ $\mathrm{A} \cdot \mathrm{U}$ major-groove triple (Fig. $6 \mathrm{~B}$ and fig. S23B). Strikingly, in the human telomerase RNA (hTR) pseudoknot, an RNA major-groove triple helix composed of three stacked U-A•Us is flanked by a quintuple-base transition motif (22) that is superimposable on that of the dENE complex with an RMSD of $\sim 1.5 \AA$ (Fig. $6 \mathrm{C}$ and fig. S23C). In conclusion, the structural motifs identified in the $\mathrm{dENE}+$ poly $(\mathrm{A})_{28}$ complex represent types of long-range interactions that are characteristic of many RNA structures.

\section{Discussion}

The high-resolution crystal structure of the dENE+poly(A) $)_{28}$ complex demonstrates that poly(A) sequestration is widely employed for cellular stabilization of polyadenylated transcripts. Although RNA stabilization by clamping the poly(A) tail or $3^{\prime}$-terminal A-rich tract within a triplex has been described before for PAN or MALAT1 lncRNAs (11, 17), the structure of the dENE+poly $(\mathrm{A})_{28}$ complex reveals novel structural features that contribute to poly(A) binding and RNA stabilization. These novel features are 1) WC/H Aminor interactions formed between poly(A) and doublestranded helices, 2) conserved quintuple-base motifs that transition poly(A) from minor-groove interactions to majorgroove triplexes, and 3) a unique poly(A) 3 '-end binding pocket that facilitates formation of a blunt-ended triplex structure through a steric mechanism. Although the WC/H A-minor and the quintuple-base motifs exist in RNAs whose structures were previously determined (Fig. 6 and fig. S24), they were not recognized earlier as distinct structural motifs.

Several types of adenosine-minor groove interactions have been previously described, including the A-minor motif, which is the most frequently-occurring tertiary structure interaction in RNAs (18), the twisted A-minor (23), the inclined A-minor $(24,25)$ and the A-amino kissing motifs $(26)$. In the dENE structure, the WC/H A-minor motif comprises four consecutive adenosines tracking in the minor groove by interaction with the bases and ribose moieties. This interaction mode makes it possible for several consecutive adenosines to associate with a double-helical stem by alternating contacts with the two strands (Fig. 1F), distinct from previously-described minor-groove interactions. Moreover, extended $\mathrm{WC} / \mathrm{H}$ A-minor motifs apparently require $\mathrm{Y} / \mathrm{R}$ biased helices as judged by their high degree of evolutionary conservation (figs. S3, S22, and S25). Moreover, WC/H A-minor interactions are followed by quintuple-base transition mo- 
tifs if flanked by a major-groove triple(s) (Fig. 6, B and C, and fig. S23, B and C).

New structural motifs observed in the dENE+poly $(\mathrm{A})_{28}$ complex are bioinformatically predicted to occur also in many single-domain ENEs identified in transcripts produced by TEs (mostly retrotransposons) and in genomes of positive-sense RNA viruses belonging to the order Picornavirales (figs. S22 and S25) (9). Interestingly, the RNA $3{ }^{\prime}$ ends of both classes of these cell-invading agents are targeted by cellular RNA decay pathways to restrict retrotransposition or viral infection, respectively (27-29). For instance, $3^{\prime}$-end uridylation by terminal uridyltransferase $4 / 7$ (TUT4/7), which usually leads to RNA degradation, was demonstrated to potently restrict the proliferation of both retrotransposons and RNA viruses $(30,31)$. Thus, it appears that these agents evolved ENEs to counter host defense mechanisms acting on RNA $3^{\prime}$ ends. The poly(A) $3^{\prime}$-end binding pocket is particularly well suited for this function.

The dENE+poly $(\mathrm{A})_{28}$ structure coupled with current and previous bioinformatics searches (9) has revealed extensive widespread interactions of poly(A) with highly structured RNAs derived from transposons. The question arises whether such interactions occur more broadly in non-transposon derived cellular polyadenylated RNAs. Recent genome-wide probing of mRNA structure and decay led to the conclusion that double-strandedness of poly(A) tail-proximal regions enhances mRNA stability in both yeast and human cells ( 1 , $32,33)$. Is this enhancement brought about by engaging in interactions with poly(A) tails akin to those found for ENEs? Our previous bioinformatics screens for ENE-like elements (designed based on the PAN ENE structure) did not reveal canonical ENEs in either non-repetitive regions of eukaryotic genomes or mRNA and lncRNA transcriptomes except for MALAT1 and MEN $\beta \operatorname{lncRNAs}(7,9,14)$. The dENE+poly(A) 28 structure has now revealed the modular nature of this complex. Separate module(s) appearing in isolation or in combination with other yet unknown features may have escaped detection. The identification of novel structural motifs in this study raises new possibilities for designing more targeted bioinformatic searching strategies. Likewise, new experimental approaches will be needed to probe such interactions.

In conclusion, the $\mathrm{dENE}+$ poly $(\mathrm{A})_{28}$ structure in conjunction with other documented poly(A)-RNA interactions $(1,11$, $17,22,32)$ demonstrates that poly(A) is capable, perhaps more than any other homo-ribopolymer, to engage in extensive tertiary interactions to form structured RNA modules. Therefore, it is tempting to speculate that the ancestral role of poly(A) tails was to protect RNA from $3^{\prime}$-end degradation through such poly(A)-RNA interactions. Only later in evolution, with the advent of poly(A)-binding proteins, was this function relegated significantly to proteins $(34,35)$.

\section{Materials and methods}

\section{RNA preparation}

Poly(A) RNAs were purchased from Dharmacon and PAGE purified using a 14\% denaturing gel. PAGE purified poly(A) samples were dissolved in $\mathrm{ddH}_{2} \mathrm{O}$ and stored at $-80^{\circ} \mathrm{C}$ until use. All ENE RNAs used in the study were in vitro transcribed using homemade T7 RNA polymerase. In the optimal crystallization construct (Xtal), which produced the best diffraction quality crystals, the upper hairpin loop of the wild-type TWIFB1 dENE is replaced with a 4 base-pair stem producing a blunt-ended helix and the lower stem is closed by addition of a hairpin structure with GAAA tetraloop to facilitate crystal packing. The DNA template for the Xtal construct was cloned in a pUC19 plasmid with a downstream hammerhead $(\mathrm{HH})$ ribozyme and an upstream hepatitis delta virus (HDV) ribozyme to produce RNA with defined $5^{\prime}$ and $3^{\prime}$ ends (36). The Xtal RNA was prepared from the plasmid template that was linearized with EcoRI and transcribed with T7 RNA polymerase. RNA was PAGE purified and exchanged into crystallization buffer (10 mM sodium cacodylate, $\mathrm{pH} 6.5,50 \mathrm{mM} \mathrm{KCl,} 1 \mathrm{mM} \mathrm{MgCl}_{2}$ and 0.1 mM EDTA) as previously described (11). DNA templates for in vitro transcription of other ENEs not designed to be used in crystallization experiments were prepared via PCR using primers that contain the T7 RNA polymerase promoter. RNAs used for in vitro experiments were in vitro transcribed to start with $\mathrm{G}$ at their $5^{\prime}$ end to overcome low transcription yields. Except for crystallization constructs, other RNA samples were dissolved in ddH2O after PAGE purification.

${ }^{32} \mathrm{P} \quad 5^{\prime}$-end labeled poly $(\mathrm{A})_{28}$ containing $2^{\prime}, 3^{\prime}$-cyclic phosphate was generated by partial alkali digestion of a longer ${ }^{32} \mathrm{P} 5^{\prime}$-end labeled poly(A) followed by PAGE purification.

\section{Crystallization}

The Xtal+poly $(\mathrm{A})_{28}$ complex was prepared by mixing an equimolar amount of the two RNAs with a final concentration of $\sim 7.5 \mathrm{mg} / \mathrm{ml}(\sim 170 \mu \mathrm{M})$ in crystallization buffer (above). The mixture was heated at $95^{\circ} \mathrm{C}$ for $2.5 \mathrm{~min}$, snapcooled on ice for $15 \mathrm{~min}$ and allowed to equilibrate at room temperature for at least 1 hour before setting up crystallization trays. Crystals were grown at $20^{\circ} \mathrm{C}$ by the sitting drop vapor-diffusion method (37). Equal volumes of the annealed RNA sample and the reservoir solution $(50 \mathrm{mM}$ sodium cacodylate, $\mathrm{pH} 7.0,9 \mathrm{mM} \mathrm{MgCl}_{2}, 1.8 \mathrm{mM}$ cobalt (III) hexamine chloride, $0.9 \mathrm{mM}$ spermidine, $2.5 \mathrm{mM}$ spermine and 5\% PEG 400) were mixed by pipetting up and down. Crystals with rod-shape morphology (up to $\sim 500 \mu \mathrm{m} \times 50 \mu \mathrm{m} \times 50 \mu \mathrm{m}$ ) appeared within 7 to $20 \mathrm{~d}$ and were stabilized by addition of increasing amounts of glycerol to a final concentration of 
$25 \%$. The cryo protectant solution was identical to the reservoir buffer, except with $10 \mathrm{mM} \mathrm{SrCl}_{2}$ instead of $\mathrm{MgCl}_{2}$. Cryoprotected crystals were incubated at $4^{\circ} \mathrm{C}$ for 1.5 hours and flash frozen in liquid nitrogen. Heavy atom derivatives were soaked as above in a solution containing $5 \mathrm{mM}$ iridium(III) hexamine trichloride (kind gift of A. Ferré-D'Amaré, NIH Biochemistry and Biophysics Center) and then flash frozen in liquid nitrogen.

\section{Data collection and processing}

Iridium-soaked crystals were used to collect three datasets under cryocooled conditions $(100 \mathrm{~K})$ at iridium's peak

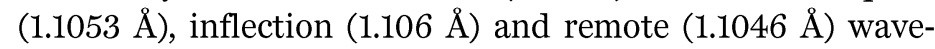
lengths at the NECAT Sector ID-24-C beamline at the Advanced Photon Source. The initial data processing was done using XDS (38); then the data were indexed, integrated and scaled in HKL2000 (39). Crystals belonged to the $\mathrm{P}_{4} 22$ space group with cell dimensions $\mathrm{a}=\mathrm{b}=93.9 \AA$, $\mathrm{c}=202.2 \AA$ and $\alpha=\beta=90.0^{\circ}, \gamma=120.0^{\circ}$. Initial experimental phases at 3.10- $\AA$ resolution were determined using the multiwavelength anomalous dispersion (MAD) method using SHELX (40) (fig. S5). A native dataset was collected at $0.9792 \AA$ at the same beamline and processed using HKL-2000 (39). The structure obtained from the MAD analysis was used as a model for molecular replacement for the native dataset at 2.89- $\AA$ resolution using Phaser (41) from the CCP4 (42). Models were built in Coot (43) and refined using Refmac (44) from the CCP4 package (42). Structural superpositions and RMSD calculations were performed using Coot (43). Structural figures were prepared using PyMol (Schrödinger, LLC).

\section{Native gel shift assays}

Trace amounts of appropriate 5 ' -radiolabeled poly(A) RNAs (final concentration $\sim 1 \mathrm{nM}$ ) were mixed with increasing concentrations of ENEs in a binding buffer containing 10 $\mathrm{mM}$ sodium cacodylate $\mathrm{pH} 7.0,50 \mathrm{mM} \mathrm{KCl}, 1 \mathrm{mM} \mathrm{MgCl}_{2}$, and $0.5 \mathrm{mg} / \mathrm{mL}$ E. coli carrier RNA, and $5 \% \mathrm{v} / \mathrm{v}$ glycerol. Samples were heated at $95^{\circ} \mathrm{C}$ for $2.5 \mathrm{~min}$, snap-cooled on ice for $10 \mathrm{~min}$, and incubated at room temperature for $\sim 1$ hour. An $8 \%$ native polyacrylamide gel prepared with $\mathrm{TH}$ buffer including $1 \mathrm{mM} \mathrm{MgCl}_{2}$ in the gel and running buffer was used to resolve complexes from unbound poly(A). Native gels were dried, exposed to a phosphorimager screen, scanned using a Storm 860 (GE Healthcare) and quantitated using ImageQuant software. Apparent dissociation constants $\left(K_{\mathrm{d}}\right)$ were determined by plotting the fraction of the ENE-bound poly(A) complex versus the initial ENE concentration and fitting the data to the following equation: Fraction of bound poly $(\mathrm{A})=0.5\left(K_{\mathrm{d}}+\mathrm{E}+\mathrm{A}\right)-0.5\left[\left(K_{\mathrm{d}}+\mathrm{E}+\mathrm{A}\right)^{2}-\right.$ $4 \mathrm{EA}]^{1 / 2}$. In this equation $\mathrm{E}$ and $\mathrm{A}$ are the initial concentrations of ENE and poly(A), respectively.

\section{Beta-globin reporter assays}

The reporter assay and the $\beta \Delta 1,2$ plasmid used were previously described (6). Reporter assays in this study were performed with slight modification. Different ENE-containing plasmids were generated by inserting the ENE into the ApaI site of the reporter construct and mutants were produced as described (9). HEK293T cells were grown in DMEM medium with $10 \%$ fetal bovine serum, $2 \mathrm{mM}$ L-glutamine and $1 \times$ penicillin-streptomycin at $37^{\circ} \mathrm{C}$ and $5 \% \mathrm{CO}_{2}$. Cells were transfected with $\beta$-globin reporter plasmids using TransIT293 (Mirus) according to the manufacturer's protocol. RNA was isolated $\sim 45$ hours post-transfection using Trizol reagent (Life Technologies). For Northern blot analyses, RNAs from different samples were resolved on a $1.4 \%$ agarose $/ 6.5 \%$ formaldehyde gel and transferred to Zeta-Probe GT membranes (Bio-Rad). Blots were probed for $\beta$-globin and NeoR mRNAs expressed from the same plasmid. First, blots were probed for $\mathrm{Neo}^{\mathrm{R}}$ mRNA using mixture of three ${ }^{32}$ P-labeled DNA probes: $5^{\prime}$ GCATCAGAGCAGCCGATTGTCTGTTG-3', 5 ' GCATCAGCCATGATGGATACTTTCTCGG-3 ${ }^{\prime}$, and $5^{\prime}$ GGCCATTTTCCACCATGATATTCGGCAAGC- 3 '. To detect $\beta$ globin transcripts, blots were probed using six ${ }^{32} \mathrm{P}$-labeled DNA probes: 5 ' -GCCGCTTAGTGATACTTGTGGGCCAGGGC$3^{\prime}, \quad 5^{\prime}$-GCCACACCAGCCACCACTTTCTGATAGGC-3' , 5 5' $^{\prime}$ GTGTGGCAAAGGTGCCCTTGAGGTTGTCCAGG-3' , GGCACCGAGCACTTTCTTGCCATGAGCCTTC-3', $5{ }^{\prime}$ GCCTCACCACCAACTTCATCCACGTTCACCTTGC-3', and 5 ' -GGTGCACCTTGTCATCGTCGTCCTTGTAGTC-3' .

Blots were exposed to a phosphorimager screen, scanned using a Storm 860 (GE Healthcare), and quantitated using ImageQuant software. Fold accumulation of $\beta$ globin transcripts was calculated by first dividing the $\beta$ globin signal in each lane by that of $\mathrm{Neo}^{\mathrm{R}}$, which provided a loading and transfection control. The signal from the $\beta \Delta 1,2$ plasmid, with no ENE to stabilize the transcript was set at 1.0 to calculate the normalized fold-accumulation of $\beta$ globin for each construct. At least four independent experiments were performed.

\section{Deadenylation assay}

Deadenylation assays were performed in HeLa nuclear extract based on a previously published protocol (45) with slight modifications. DNA templates were prepared by PCR to include ENEs upstream of a DNA-encoded poly(A) tail (either poly $(\mathrm{A})_{72}$, poly $(\mathrm{A})_{69} \mathrm{G}(\mathrm{A})_{2}$ or $\left.\operatorname{poly}(\mathrm{A})_{69} \mathrm{G}(\mathrm{A})_{22}\right)$. ${ }^{32} \mathrm{P}-$ internally labeled RNAs were prepared by in vitro transcribing RNA in the presence of [ $\left.\alpha^{32} \mathrm{P}\right]-\mathrm{UTP}$ using T7 RNA polymerase and purified by denaturing PAGE. We used the vaccinia capping system from New England Biolabs (NEB) to add 7-methylguanylate caps to the $5^{\prime}$ ends of RNAs (46). Deadenylation reactions for each construct consisted of 45 
$\mu$ solution containing $100 \mathrm{mM} \mathrm{KCl}, 0.5 \mathrm{mM} \mathrm{MgCl}_{2}, 3 \%$ polyvinyl alcohol, $18 \mathrm{ng} / \mu \mathrm{l}$ poly(A) (Sigma), 1 unit/ $/ \mathrm{l}$ RNase inhibitor (Roche), $8 \mathrm{mM}$ HEPES, pH 7.9, $0.08 \mathrm{mM}$ EDTA, $40 \%$ Dignam nuclear extract (47) and $\sim 10 \mathrm{nM}$ RNA substrate. Reactions were incubated at $30^{\circ} \mathrm{C}$, and $5 \mu \mathrm{l}$ aliquots were removed at 15, 30, 60, 90 and $120 \mathrm{~m}$. Fully deadenylated RNA was generated by adding $1 \mu \mathrm{L}$ of $80 \mu \mathrm{M}$ oligo(dT) $)_{40}$ to the reaction and incubating for $20 \mathrm{~min}$ at $37^{\circ} \mathrm{C}$ to take the advantage of the enzymatic activity of endogenous RNase $\mathrm{H}$ in the extract. The no deadenylation control was not exposed to nuclear extract. Following PCA extraction and RNA precipitation, samples were separated using a 7\% denaturing gel. Gels were dried and exposed to a phosphorimager screen.

\section{REFERENCES AND NOTES}

1. J. V. Geisberg, Z. Moqtaderi, X. Fan, F. Ozsolak, K. Struhl, Global analysis of mRNA isoform half-lives reveals stabilizing and destabilizing elements in yeast. Cell 156, 812-824 (2014). doi:10.1016/i.cell.2013.12.026 Medline

2. M. Kim, N. Kogan, F. J. Slack, Cis-acting elements in its 3' UTR mediate posttranscriptional regulation of KRAS. Oncotarget 7, 11770-11784 (2016). doi:10.18632/oncotarget.7599 Medline

3. O. Mizrahi, A. Nachshon, A. Shitrit, I. A. Gelbart, M. Dobesova, S. Brenner, C. Kahana, N. Stern-Ginossar, Virus-induced changes in mRNA secondary structure uncover cis-regulatory elements that directly control gene expression. Mol. Cell 72, 862-874.e5 (2018). doi:10.1016/i.molcel.2018.09.003

4. C. E. Vejnar, M. Abdel Messih, C. M. Takacs, V. Yartseva, P. Oikonomou, R. Christiano, M. Stoeckius, S. Lau, M. T. Lee, J.-D. Beaudoin, D. Musaev, H. Darwich-Codore, T. C. Walther, S. Tavazoie, D. Cifuentes, A. J. Giraldez, Genome wide analysis of $3^{\prime}$ UTR sequence elements and proteins regulating mRNA stability during maternal-to-zygotic transition in zebrafish. Genome Res. 29 , 1100-1114 (2019). doi:10.1101/gr.245159.118 Medline

5. B. M. Akiyama, D. Eiler, J. S. Kieft, Structured RNAs that evade or confound exonucleases: Function follows form. Curr. Opin. Struct. Biol. 36, 40-47 (2016). doi:10.1016/i.sbi.2015.12.006 Medline

6. N. K. Conrad, J. A. Steitz, A Kaposi's sarcoma virus RNA element that increases the nuclear abundance of intronless transcripts. EMBO J. 24, 1831-1841(2005). doi:10.1038/sj.emboj.7600662 Medline

7. J. A. Brown, M. L. Valenstein, T. A. Yario, K. T. Tycowski, J. A. Steitz, Formation of triple-helical structures by the 3 '-end sequences of MALAT1 and MEN $\beta$ noncoding RNAs. Proc. Natl. Acad. Sci. U.S.A. 109, 19202-19207 (2012). doi:10.1073/pnas.1217338109 Medline

8. J. E. Wilusz, C. K. JnBaptiste, L. Y. Lu, C.-D. Kuhn, L. Joshua-Tor, P. A. Sharp, A triple helix staロbilizes the $3^{\prime}$ ends of long noncoding RNAs that lack poly(A) tails. Genes Dev. 26, 2392-2407 (2012). doi:10.1101/gad.204438.112 Medline

9. K. T. Tycowski, M. D. Shu, J. A. Steitz, Myriad triple-helix-forming structures in the transposable element RNAs of plants and fungi. Cell Rep. 15, 1266-1276 (2016). doi:10.1016/i.celrep.2016.04.010 Medline

10. N. K. Conrad, S. Mili, E. L. Marshall, M. D. Shu, J. A. Steitz, Identification of a rapid mammalian deadenylation-dependent decay pathway and its inhibition by a viral RNA element. Mol. Cell 24, 943-953 (2006). doi:10.1016/i.molcel.2006.10.029 Medline

11. R. M. Mitton-Fry, S. J. DeGregorio, J. Wang, T. A. Steitz, J. A. Steitz, Poly(A) tail recognition by a viral RNA element through assembly of a triple helix. Science 330, 1244-1247 (2010). doi:10.1126/science.1195858 Medline

12. N. K. Conrad, M. D. Shu, K. E. Uyhazi, J. A. Steitz, Mutational analysis of a viral RNA element that counteracts rapid RNA decay by interaction with the polyadenylate tail. Proc. NatI. Acad. Sci. U.S.A. 104, 10412-10417 (2007). doi:10.1073/pnas.0704187104 Medline

13. S. Borah, N. Darricarrère, A. Darnell, J. Myoung, J. A. Steitz, A viral nuclear noncoding RNA binds re-localized poly(A) binding protein and is required for late KSHV gene expression. PLOS Pathog. 7, e1002300 (2011). doi:10.1371/journal.ppat.1002300 Medline

14. K. T. Tycowski, M. D. Shu, S. Borah, M. Shi, J. A. Steitz, Conservation of a triplehelix-forming RNA stability element in noncoding and genomic RNAs of diverse viruses. Cell Rep. 2, 26-32 (2012). doi:10.1016/i.celrep.2012.05.020 Medline

15. T. Gutschner, M. Hämmerle, S. Diederichs, MALAT1-A paradigm for long noncoding RNA function in cancer. J. Mol. Med. 91, 791-801(2013). doi:10.1007/s00109-013-1028-y Medline

16. S. Dhamija, S. Diederichs, From junk to master regulators of invasion: IncRNA functions in migration, EMT and metastasis. Int. J. Cancer 139, 269-280 (2016). doi:10.1002/ijc.30039 Medline

17. J. A. Brown, D. Bulkley, J. Wang, M. L. Valenstein, T. A. Yario, T. A. Steitz, J. A. Steitz, Structural insights into the stabilization of MALAT1 noncoding RNA by a bipartite triple helix. Nat. Struct. Mol. Biol. 21, 633-640 (2014). doi:10.1038/nsmb.2844 Medline

18. P. Nissen, J. A. Ippolito, N. Ban, P. B. Moore, T. A. Steitz, RNA tertiary interactions in the large ribosomal subunit: The A-minor motif. Proc. Natl. Acad. Sci. U.S.A. 98, 4899-4903 (2001). doi:10.1073/pnas.081082398 Medline

19. J. A. Brown, Unraveling the structure and biological functions of RNA triple helices. Wiley Interdiscip. Rev. RNA 11, e1598 (2020). doi:10.1002/wrna.1598 Medline

20. A. L. Edwards, F. E. Reyes, A. Héroux, R. T. Batey, Structural basis for recognition of S-adenosylhomocysteine by riboswitches. RNA 16, 2144-2155 (2010). doi:10.1261/rna.2341610 Medline

21. M. Yamada, Y. Watanabe, J. S. Gootenberg, H. Hirano, F. A. Ran, T. Nakane, R. Ishitani, F. Zhang, H. Nishimasu, O. Nureki, Crystal structure of the minimal Cas9 from campylobacter jejuni reveals the molecular diversity in the CRISPR-Cas9 systems. Mol. Cell 65, 1109-1121.e3 (2017). doi:10.1016/i.molcel.2017.02.007 Medline

22. N. K. Kim, Q. Zhang, J. Zhou, C. A. Theimer, R. D. Peterson, J. Feigon, Solution structure and dynamics of the wild-type pseudoknot of human telomerase RNA. J. Mol. Biol. 384, 1249-1261(2008). doi:10.1016/j.jmb.2008.10.005 Medline

23. S. D. Gilbert, R. P. Rambo, D. Van Tyne, R. T. Batey, Structure of the SAM-II riboswitch bound to S-adenosylmethionine. Nat. Struct. Mol. Biol. 15, 177-182 (2008). doi:10.1038/nsmb.1371 Medline

24. D. J. Klein, T. E. Edwards, A. R. Ferré-D'Amaré, Cocrystal structure of a class I preQ1 riboswitch reveals a pseudoknot recognizing an essential hypermodified nucleobase. Nat. Struct. Mol. Biol. 16, 343-344 (2009). doi:10.1038/nsmb.1563 Medline

25. J. A. Liberman, K. C. Suddala, A. Aytenfisu, D. Chan, I. A. Belashov, M. Salim, D. H. Mathews, R. C. Spitale, N. G. Walter, J. E. Wedekind, Structural analysis of a class III preQ1 riboswitch reveals an aptamer distant from a ribosome-binding site regulated by fast dynamics. Proc. Natl. Acad. Sci. U.S.A. 112, E3485-E3494 (2015). doi:10.1073/pnas.1503955112 Medline

26. M. Kang, R. Peterson, J. Feigon, Structural Insights into riboswitch control of the biosynthesis of queuosine, a modified nucleotide found in the anticodon of tRNA. Mol. Cell 33, 784-790 (2009). doi:10.1016/j.molcel.2009.02.019 Medline

27. J. M. Molleston, S. Cherry, Attacked from all sides: RNA decay in antiviral defense. Viruses 9, 2 (2017). doi:10.3390/v9010002 Medline

28. J. Yeo, V. N. Kim, U-tail as a guardian against invading RNAs. Nat. Struct. Mol. Biol. 25, 903-905 (2018). doi:10.1038/s41594-018-0139-0 Medline

29. J. C. Zinder, C. D. Lima, Targeting RNA for processing or destruction by the eukaryotic RNA exosome and its cofactors. Genes Dev. 31, 88-100 (2017). doi:10.1101/gad.294769.116 Medline

30. Z. Warkocki, P. S. Krawczyk, D. Adamska, K. Bijata, J. L. Garcia-Perez, A. Dziembowski, Uridylation by TUT4/7 restricts retrotransposition of human LINE- 
1s. Cell 174, 1537-1548.e29 (2018). doi:10.1016/i.cell.2018.07.022 Medline

31. J. Le Pen, H. Jiang, T. Di Domenico, E. Kneuss, J. Kosałka, C. Leung, M. Morgan, C. Much, K. L. M. Rudolph, A. J. Enright, D. O'Carroll, D. Wang, E. A. Miska, Terminal uridylyltransferases target RNA viruses as part of the innate immune system. Nat. Struct. Mol. Biol. 25, 778-786 (2018). doi:10.1038/s41594-0180106-9 Medline

32. Z. Moqtaderi, J. V. Geisberg, K. Struhl, Secondary structures involving the poly $(A)$ tail and other 3 ' sequences are major determinants of mRNA isoform stability in yeast. Microb. Cell 1, 137-139 (2014). doi:10.15698/mic2014.04.140 Medline

33. X. Wu, D. P. Bartel, Widespread influence of 3'-end structures on mammalian mRNA processing and stability. Cell 169, 905-917.e11(2017). doi:10.1016/i.cell.2017.04.036 Medline

34. I. B. Schäfer, M. Yamashita, J. M. Schuller, S. Schüssler, P. Reichelt, M. Strauss, E. Conti, Molecular basis for poly(A) RNP architecture and recognition by the Pan2-Pan3 deadenylase. Cell 177, 1619-1631.e21(2019). doi:10.1016/i.cell.2019.04.013 Medline

35. C. P. Wigington, K. R. Williams, M. P. Meers, G. J. Bassell, A. H. Corbett, Poly(A) RNA-binding proteins and polyadenosine RNA: New members and novel functions. Wiley Interdiscip. Rev. RNA 5, 601-622(2014). doi:10.1002/wrna.1233 Medline

36. J. M. Avis, G. L. Conn, S. C. Walker, Cis-acting ribozymes for the production of RNA in vitro transcripts with defined $5^{\prime}$ and $3^{\prime}$ ends. Methods Mol. Biol. 941, 8398 (2012). doi:10.1007/978-1-62703-113-4 7 Medline

37. B. L. Golden, C. E. Kundrot, RNA crystallization. J. Struct. Biol. 142, 98-107 (2003). doi:10.1016/S1047-8477(03)00042-X Medline

38. W. Kabsch, Xds. Acta Crystallogr. D 66, 125-132 (2010). doi:10.1107/S0907444909047337 Medline

39. Z. Otwinowski, W. Minor, Processing of X-ray diffraction data collected in oscillation mode. Methods Enzymol. 276, 307-326 (1997). doi:10.1016/S00766879(97)76066-X

40. G. M. Sheldrick, Experimental phasing with SHELXC/D/E: Combining chain tracing with density modification. Acta Crystallogr. D 66, 479-485 (2010). doi:10.1107/S0907444909038360 Medline

41. A. J. McCoy, R. W. Grosse-Kunstleve, P. D. Adams, M. D. Winn, L. C. Storoni, R. J. Read, Phaser crystallographic software. J. Appl. Crystallogr. 40, 658-674 (2007). doi:10.1107/S0021889807021206 Medline

42. M. D. Winn, C. C. Ballard, K. D. Cowtan, E. J. Dodson, P. Emsley, P. R. Evans, R. M. Keegan, E. B. Krissinel, A. G. W. Leslie, A. McCoy, S. J. McNicholas, G. N. Murshudov, N. S. Pannu, E. A. Potterton, H. R. Powell, R. J. Read, A. Vagin, K. S. Wilson, Overview of the CCP4 suite and current developments. Acta Crystallogr. D 67, 235-242 (2011). doi:10.1107/S0907444910045749 Medline

43. P. Emsley, B. Lohkamp, W. G. Scott, K. Cowtan, Features and development of Coot. Acta Crystallogr. D 66, 486-501(2010). doi:10.1107/S0907444910007493 Medline

44. G. N. Murshudov, A. A. Vagin, E. J. Dodson, Refinement of macromolecular structures by the maximum-likelihood method. Acta Crystallogr. D53, 240-255 (1997). doi:10.1107/S09074444996012255 Medline

45. L. P. Ford, J. Watson, J. D. Keene, J. Wilusz, ELAV proteins stabilize deadenylated intermediates in a novel in vitro mRNA deadenylation/degradation system. Genes Dev. 13, 188-201 (1999). doi:10.1101/gad.13.2.188 Medline

46. A. L. Fuchs, A. Neu, R. Sprangers, A general method for rapid and cost-efficient large-scale production of 5' capped RNA. RNA 22, 1454-1466 (2016). doi:10.1261/rna.056614.116 Medline

47. J. D. Dignam, R. M. Lebovitz, R. G. Roeder, Accurate transcription initiation by RNA polymerase II in a soluble extract from isolated mammalian nuclei. Nucleic Acids Res. 11, 1475-1489 (1983). doi:10.1093/nar/11.5.1475 Medline

48. N. B. Leontis, E. Westhof, Geometric nomenclature and classification of RNA base pairs. RNA 7, 499-512 (2001). doi:10.1017/S1355838201002515 Medline
49. R. M. Bock, Controlled partial hydrolysis of RNA. Methods Enzymol. 12, 218-221 (1967). doi:10.1016/S0076-6879(67)12033-8

50. G. P. Pijlman, A. Funk, N. Kondratieva, J. Leung, S. Torres, L. van der Aa, W. J. Liu, A. C. Palmenberg, P.-Y. Shi, R. A. Hall, A. A. Khromykh, A highly structured, nuclease-resistant, noncoding RNA produced by flaviviruses is required for pathogenicity. Cell Host Microbe 4, 579-591(2008). doi:10.1016/i.chom.2008.10.007 Medline

51. R. Rauhut, G. Klug, mRNA degradation in bacteria. FEMS Microbiol. Rev. 23, 353370 (1999). do::10.1111/i.1574-6976.1999.tb00404.x Medline

52. B. M. Akiyama, H. M. Laurence, A. R. Massey, D. A. Costantino, X. Xie, Y. Yang, P.Y. Shi, J. C. Nix, J. D. Beckham, J. S. Kieft, Zika virus produces noncoding RNAs using a multi-pseudoknot structure that confounds a cellular exonuclease. Science 354, 1148-1152 (2016). doi:10.1126/science.aah3963 Medline

53. A. L. Steckelberg, B. M. Akiyama, D. A. Costantino, T. L. Sit, J. C. Nix, J. S. Kieft, A folded viral noncoding RNA blocks host cell exoribonucleases through a conformationally dynamic RNA structure. Proc. Natl. Acad. Sci. U.S.A. 115, 6404-6409 (2018). doi:10.1073/pnas.1802429115 Medline

54. A. L. Steckelberg, Q. Vicens, D. A. Costantino, J. C. Nix, J. S. Kieft, The crystal structure of a Polerovirus exoribonuclease-resistant RNA shows how diverse sequences are integrated into a conserved fold. RNA 26, 1767-1776 (2020). doi:10.1261/rna.076224.120 Medline

55. S. Meyer, C. Temme, E. Wahle, Messenger RNA turnover in eukaryotes: Pathways and enzymes. Crit. Rev. Biochem. Mol. Biol. 39, 197-216 (2004). doi:10.1080/10409230490513991 Medline

56. S. Yu, V. N. Kim, A tale of non-canonical tails: Gene regulation by posttranscriptional RNA tailing. Nat. Rev. Mol. Cell Biol. 21, 542-556 (2020). doi:10.1038/s41580-020-0246-8 Medline

57. M. Lingaraju, J. M. Schuller, S. Falk, P. Gerlach, F. Bonneau, J. Basquin, C. Benda E. Conti, To process or to decay: A mechanistic view of the nuclear RNA exosome. Cold Spring Harb. Symp. Quant. Biol. 84, 155-163 (2019). doi:10.1101/sab.2019.84.040295 Medline

58. E. V. Wasmuth, K. Januszyk, C. D. Lima, Structure of an Rrp6-RNA exosome complex bound to poly(A) RNA. Nature 511, 435-439 (2014). doi:10.1038/nature13406 Medline

59. J. C. Zinder, E. V. Wasmuth, C. D. Lima, Nuclear RNA exosome at 3.1 A reveals substrate specificities, RNA paths, and allosteric inhibition of Rrp44/Dis3. Mol. Cell 64, 734-745 (2016). doi:10.1016/i.molcel.2016.09.038 Medline

60. W. K. Olson, S. Li, T. Kaukonen, A. V. Colasanti, Y. Xin, X.-J. Lu, Effects of noncanonical base pairing on RNA folding: Structural context and spatial arrangements of G.A Pairs. Biochemistry 58, 2474-2487 (2019). doi:10.1021/acs. biochem.9b00122 Medline

61. D. J. Proctor, H. Ma, E. Kierzek, R. Kierzek, M. Gruebele, P. C. Bevilacqua, Folding thermodynamics and kinetics of YNMG RNA hairpins: Specific incorporation of 8 bromoguanosine leads to stabilization by enhancement of the folding rate. Biochemistry 43, 14004-14014 (2004). doi:10.1021/bi048213e Medline

62. K. B. Hall, Mighty tiny. RNA 21, 630-631 (2015). doi:10.1261/rna.050567.115 Medline

63. D. J. Battle, J. A. Doudna, Specificity of RNA-RNA helix recognition. Proc. Natl. Acad. Sci. U.S.A. 99, 11676-11681 (2002). doi:10.1073/pnas.182221799 Medline

64. A. Lescoute, E. Westhof, The A-minor motifs in the decoding recognition process. Biochimie 88, 993-999 (2006). doi:10.1016/i.biochi.2006.05.018 Medline

65. Y. Xin, C. Laing, N. B. Leontis, T. Schlick, Annotation of tertiary interactions in RNA structures reveals variations and correlations. RNA 14, 2465-2477 (2008). do:i:10.1261/rna.1249208 Medline

66. L. Wu, D. Chai, M. E. Fraser, S. Zimmerly, Structural variation and uniformity among tetraloop-receptor interactions and other loop-helix interactions in RNA crystal structures. PLOS ONE 7, e49225 (2012). doi:10.1371/journal.pone.0049225 Medline

67. L. D'Ascenzo, Q. Vicens, P. Auffinger, Identification of receptors for UNCG and GNRA Z-turns and their occurrence in rRNA. Nucleic Acids Res. 46, 7989-7997 
(2018). doi:10.1093/nar/gky578 Medline

68. C. Bou-Nader, J. Zhang, Structural insights into RNA dimerization: Motifs, interfaces and functions. Molecules 25, 2881 (2020).

doi:10.3390/ $\square$ molecules25122881 Medline

69. S. L. Vi, G. Trost, P. Lange, H. Czesnick, N. Rao, D. Lieber, T. Laux, W. M. Gray, J. L. Manley, D. Groth, C. Kappel, M. Lenhard, Target specificity among canonical nuclear poly(A) polymerases in plants modulates organ growth and pathogen response. Proc. Natl. Acad. Sci. U.S.A. 110, 13994-13999 (2013).

doi:10.1073/pnas.1303967110 Medline

70. L. Minvielle-Sebastia, P. J. Preker, T. Wiederkehr, Y. Strahm, W. Keller, The major yeast poly(A)-binding protein is associated with cleavage factor IA and functions in premessenger RNA 3'-end formation. Proc. Natl. Acad. Sci. U.S.A. 94, 78977902 (1997). doi:10.1073/pnas.94.15.7897 Medline

71. A. O. Subtelny, S. W. Eichhorn, G. R. Chen, H. Sive, D. P. Bartel, Poly(A)-tail profiling reveals an embryonic switch in translational control. Nature 508, 66-71 (2014). doi:10.1038/nature13007 Medline

72. H. Chang, J. Lim, M. Ha, V. N. Kim, TAIL-seq: Genome-wide determination of poly(A) tail length and 3 ' end modifications. Mol. Cell 53, 1044-1052 (2014). doi:10.1016/i.molcel.2014.02.007 Medline

73. D. P. Giedroc, P. V. Cornish, Frameshifting RNA pseudoknots: Structure and mechanism. Virus Res. 139, 193-208 (2009). do::10.1016/i,virusres.2008.06.008 Medline

74. P. A. Karplus, K. Diederichs, Linking crystallographic model and data quality. Science 336, 1030-1033 (2012). doi:10.1126/science.1218231 Medline

75. P. A. Karplus, K. Diederichs, Assessing and maximizing data quality in macromolecular crystallography. Curr. Opin. Struct. Biol. 34, 60-68 (2015). doi:10.1016/i.sbi.2015.07.003 Medline

\section{ACKNOWLEDGMENTS}

We thank P. Moore, R. Mitton-Fry and K. Zahn for critical reading of the manuscript; A. Miccinello for editorial work; and both Steitz laboratories for helpful discussion. We thank A. Ferré-D'Amaré for the generous gift of iridium(III) hexamine trichloride. Special thanks to W. Eliason, T.A. Yario and P. Raccuia for technical assistance; J.A. Brown and R. Mitton-Fry for thoughtful discussions; and the staff of the Advanced Photon Source beamline NECAT 24-ID, where X-ray data were collected. Funding: Financial support for this research was provided by NIH grant P01CA16038 to J.A.S. and NIH grant P01GM022778 to T.A.S. S.-F. T. is supported by a Damon Runyon Cancer Research Foundation Postdoctoral fellowship (DRG225716). J.A.S. is an investigator of the Howard Hughes Medical Institute. Author contributions: S.-F.T. designed and performed biochemical and structural experiments; S.-F.T. and A.V. designed and carried out crystallization, S.-F.T., A.V. and J.W. analyzed data, carried out model building and structure refinement; K.T. performed bioinformatics analysis; S.-F.T. and S.J.D. carried out cloning experiments and RNA preparation; S.-F.T. and M.-D. S. performed $\beta$-globin assays; and J.A.S designed experiments. J.A.S. and T.A.S. oversaw research. S.-F.T., K.T. and J.A.S. drafted and finalized the paper and all authors discussed the results and provided input on the manuscript. Competing interests: The authors declare no competing interests. Data and materials availability: The atomic coordinates and the structure factors can be accessed in the Protein Data Bank (ID 7JNH).

\section{SUPPLEMENTARY MATERIALS}

science.sciencemag.org/cgi/content/full/science.abe6523/DC1

Supplementary Text

Figs. S1 to S25

Table S1

References (49-75)

MDAR Reproducibility Checklist

View/request a protocol for this paper from Bio-protocol.

4 September 2020; accepted 20 November 2020

Published online 7 January 2021

$10.1126 /$ science.abe6523 


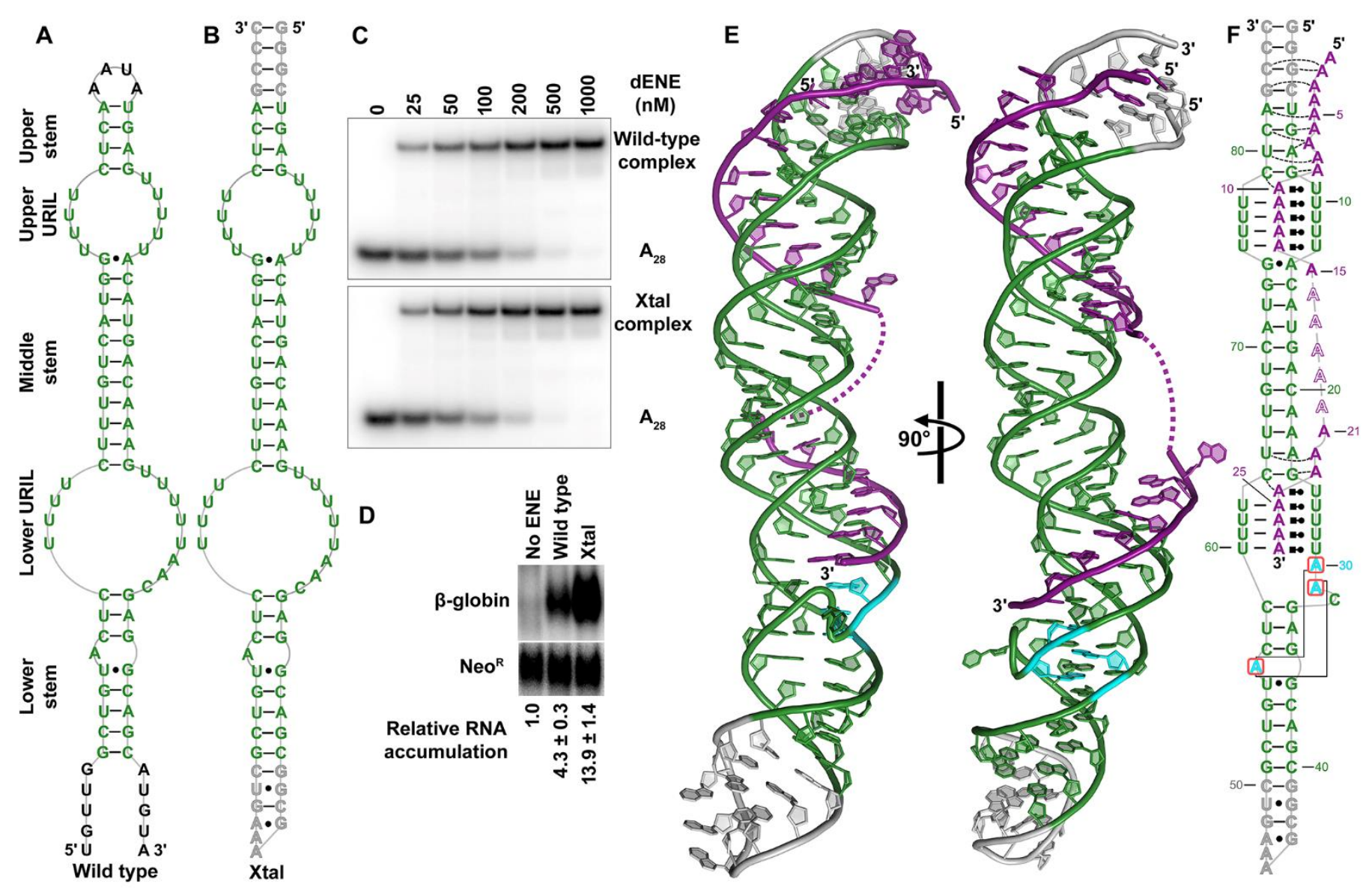

Fig. 1. Structural overview of the TWIFB1 dENE+poly $(A)_{28}$ complex. (A and B) Predicted secondary structures of the wild-type dENE (A) and of the crystallization construct (Xtal) (B), which was used to determine the X-ray structure in (E). The dENE core is shown in green. Non-native sequences in Xtal are in gray. (C) Interactions between ${ }^{32} \mathrm{P} 5^{\prime}$ '-end labeled poly $(A)_{28}$ and dENE constructs were evaluated by native gel shift assays. (D) Northern blot analysis of the $\beta \Delta 1,2$ reporter transcript abundance in HEK293T cells. Values are the average of at least four biological replicates \pm standard deviation. (E) Cartoon representation of the crystal structure, with poly $(A)_{28}$ in purple, the ENE core in green, the three adenosines engaged in base-stacking interactions (adenosine triad) in cyan, and non-native sequences in gray. ( $F$ ) Schematic diagram of the complex tertiary structure. Leontis-Westhof notation (48) is used for Hoogsteen base pairs, bullets for noncanonical base pairs and dashed lines for poly $(A)$ interactions with the minor grooves of the stems. Longrange interactions observed in the pocket structure between stacked adenines (boxed in red) are indicated by solid lines. Disordered nucleotides, $A_{16}-A_{20}$, are indicated by dashes in $(E)$ or outlined letters in $(F)$. 


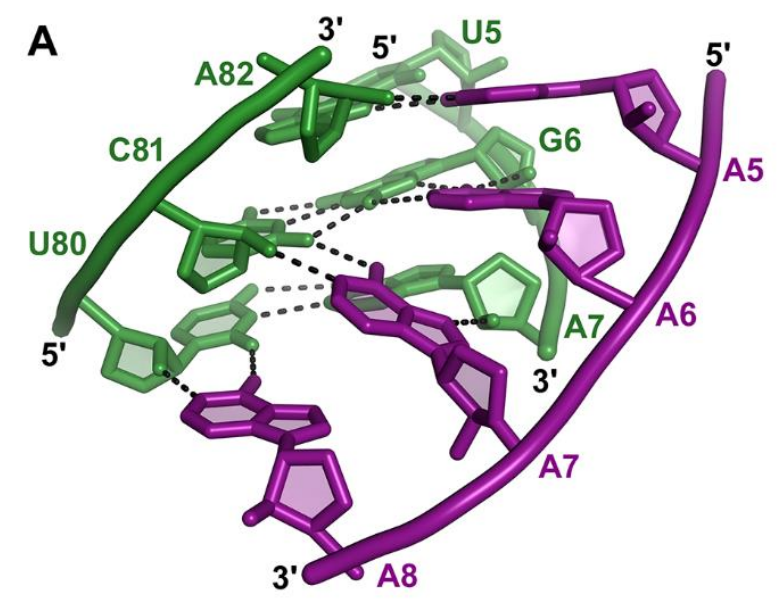

WC/H A-minor motif

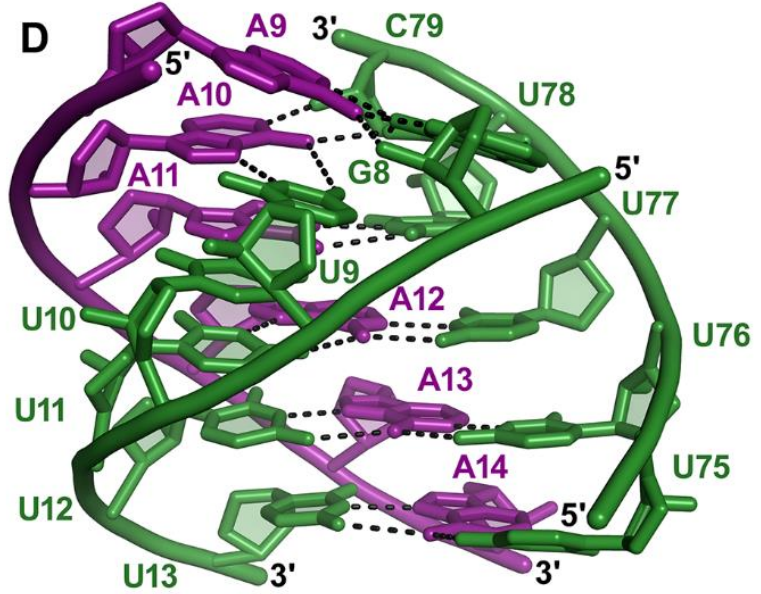

Quintuple-base transition and major-groove triplex
B

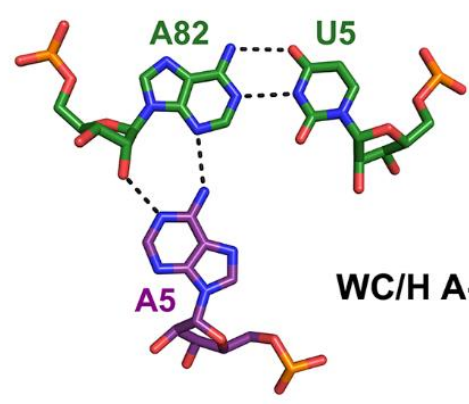

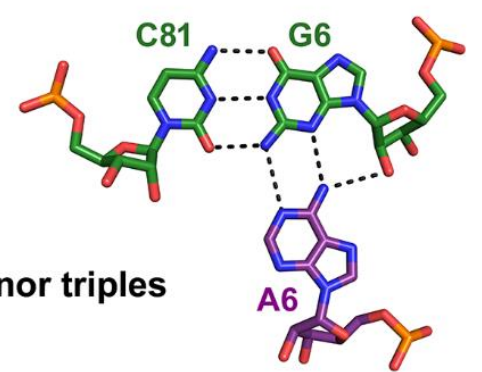

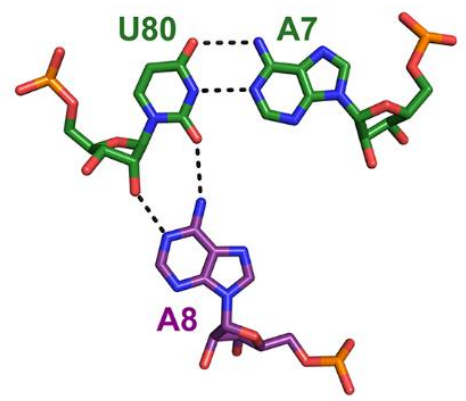

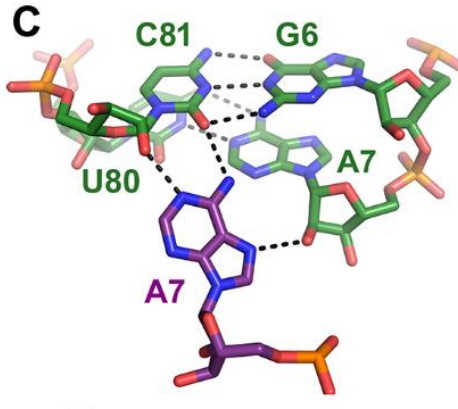

WC/H A-minor quintuple

E

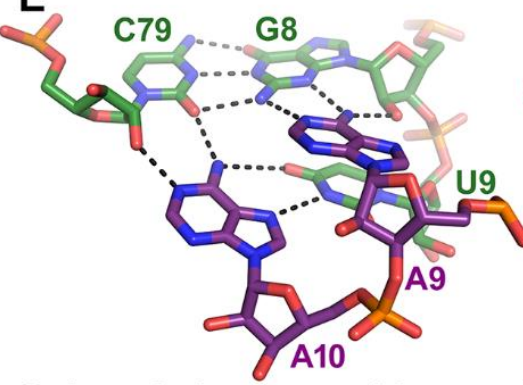

Quintuple-base transition motif

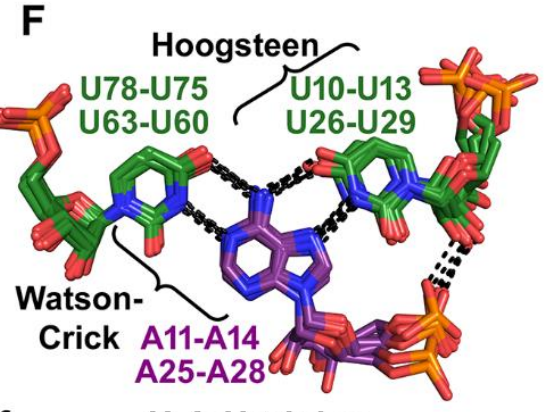

$\mathrm{U}-\mathrm{A} \cdot \mathrm{U}$ triples

Fig. 2. Hydrogen-bonding interactions in the upper ENE domain of the dENE+poly $(A)_{28}$ complex. Colors are as in Fig. 1 , with nucleotide labels also color coded. Watson-Crick base pairing and hydrogen bonds involving poly $(A)$ are represented by black dashed lines. (A) Close-up of the WC/H A-minor motif that poly (A) forms with the upper stem. (B and $\mathrm{C}$ ) The WC/H A-minor motif includes three base triples (B) and one quintuple-nucleotide interaction (C), in which poly $(A)$ adenines use their Watson-Crick and/or Hoogsteen edges to interact with the minor groove of the upper stem. (D) Close-up of the poly(A) transition from the WC/H A-minor motif to the major-groove triple helix. (E) Poly(A) makes this transition through formation of a network of hydrogen bonds involving A9 and A10 from poly(A), the C79-G8 base pair and U9. The Hoogsteen face of A10 base pairs with the Watson-Crick face of U9, while its Watson-Crick face interacts with the C79-G8 base pair minor groove. (F) Superposition of canonical U-A $\bullet U$ triples that form major-groove triplexes in the structure. 


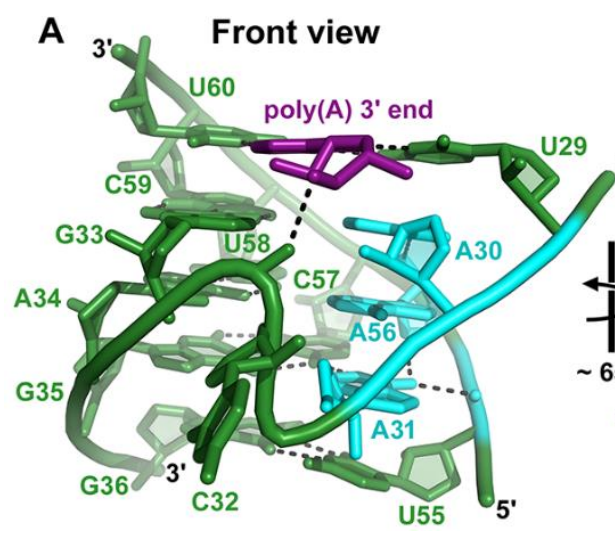

B

Side view

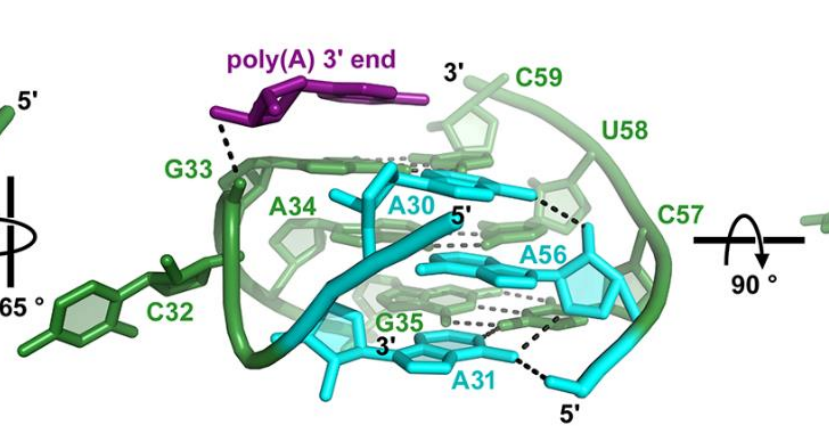

C

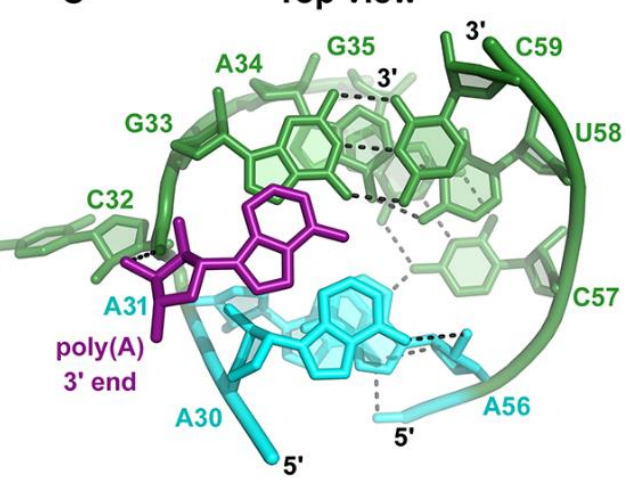

Fig. 3. Key interactions that form the poly(A) $3^{\prime}$-end binding pocket. (A) Close-up overview of the poly(A) transition from the lower dENE major-groove triplex to the flanking double helix (dENE sequence in green). The poly $(A) 3^{\prime}$-end binding pocket formed by the stacked nucleobases of the adenosine triad (cyan) lies in the major groove of a 3-base-pair long flanking double helix. The U60-A28.U29 triple and the U55•G36 base pair flanking the pocket are shown only in the front view. (B and C) Side and top views of the pocket, respectively. The $3^{\prime}$ end of poly $(A)$ is in purple. The base of A56 stacks between those of $A 30$ and $A 31$, while forming multiple hydrogen bonds with these two dENE nucleotides. The flipped out nucleobase of C32 contributes to the flexibility of the backbone and allows formation of the Z-shaped structure of the sugarphosphate backbone. The poly(A) 3' end is poised above the pocket with its $3^{\prime}$ - $\mathrm{OH}$ within hydrogen-bonding distance of the G33 phosphate oxygen. 
Fig. 4 (next page). The TWIFB1 dENE pocket motif blocks the poly(A) exit path, forming a 3 ' blunt-ended triplex. (A) Molecular surface representations of different ENEs oriented to show the direction of poly $(A) / A$-rich tract (white open arrow), the $3^{\prime}$-most adenosine of each major-groove triplex and its surrounding region. (B) Superposition of the triple helices from various ENEs using the last four $\mathrm{U}-\mathrm{A} \cdot \mathrm{U}$ triples and three base pairs of their flanking stems. The upper $\mathrm{dENE}$ domain is superimposed on the PAN or MALAT1 ENE with an RMSD $=1.1$ or $1.2 \AA$, respectively. In the superposition of the two dENE domains, only the major-groove triple helices were used (RMSD $=0.7 \AA$ ). The upper dENE triplex on the right is shown in transparent colors. The red-colored region represents a predicted steric clash that would occur between the backbone of poly $(A)$ and the pocket motif if the poly $(A)$ strand left the major-groove triplex in the lower dENE domain. The PAN and MALAT1 triplex structures were derived from PDB 3P22 (11) and 4PLX (17), respectively. (C) Cartoon representation of the TWIFB1 dENE with a 72-mer poly(A) tail. The Us changed to Cs in M26 are circled in orange. (D) In vitro deadenylation assays show that the wild-type dENE protects downstream poly $(A)$ from deadenylation, while the absence of the pocket in M11 abrogates this ability. In M26, part of the poly $(A)$ tail is trimmed rapidly and a product of the same size as that of the wild-type dENE-poly $(A)_{72}$ accumulates. dT lanes show transcripts fully deadenylated by endogenous RNase $\mathrm{H}$ in the HeLa cell nuclear extract after addition of oligo(dT) $)_{40}$ to the reaction.

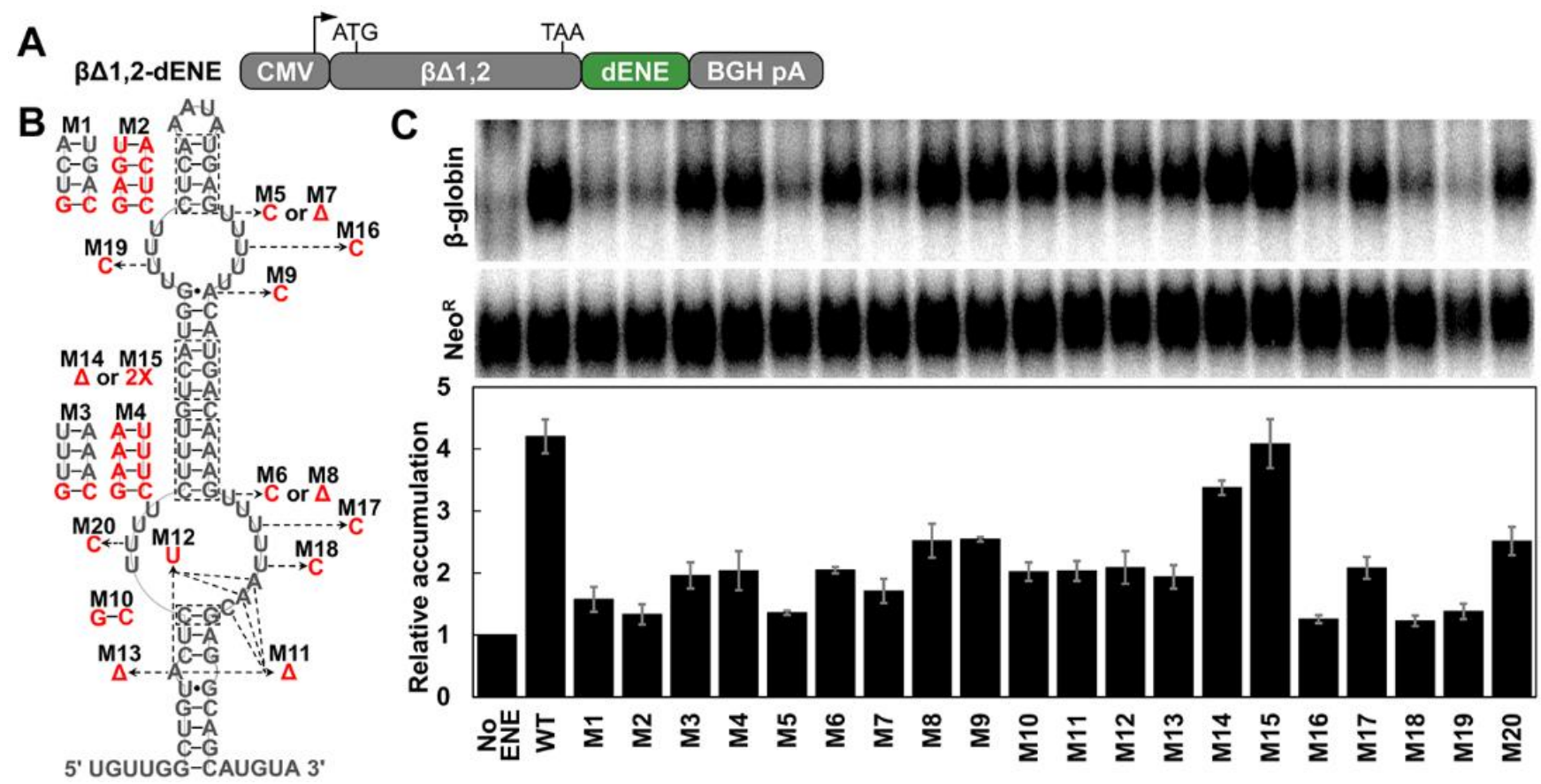

Fig. 5. Functional significance of dENE structural features contributing to the stabilization and accumulation of the $\beta$-globin reporter mRNA containing different dENE mutations. (A) Schematic of the $\beta \triangle 1,2$-dENE construct containing a CMV promoter, a human $\beta \triangle 1,2$ gene and a bovine growth hormone poly(A) site (BGH pA). (B) Schematic of the dENE predicted secondary structure highlighting the mutations studied in the assay. Gray is wild-type sequence, mutated nucleotides are red and $\Delta$ represents nucleotide deletion/s. In M12, all three As of the adenosine triad are substituted by U. (C) Northern blots (top) probed for $\beta$-globin and neomycin resistance $\left(\mathrm{Neo}^{\mathrm{R}}\right)$ sequences. Quantification of the Northern blots (bottom) with the $\beta$-globin signals normalized to those of $\mathrm{Neo}^{\mathrm{R}}$. Accumulation with No ENE was set at 1. Relative accumulation is the average of at least three independent experiments \pm standard deviation. 
A

ENEs with an open exit path for the poly(A)/A-rich tract
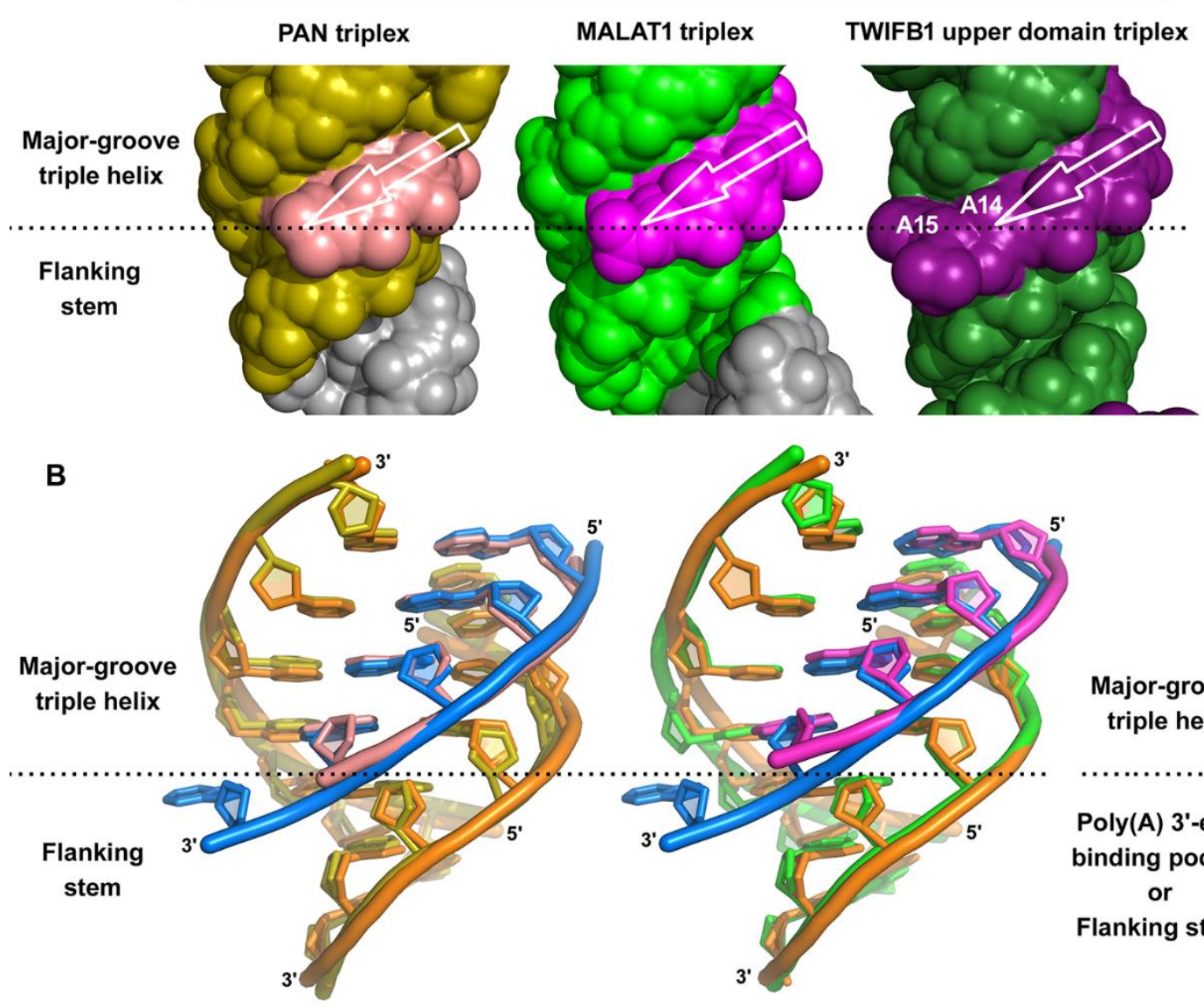

PAN ENE - poly(A) TWIFB1 upper ENE - poly(A)

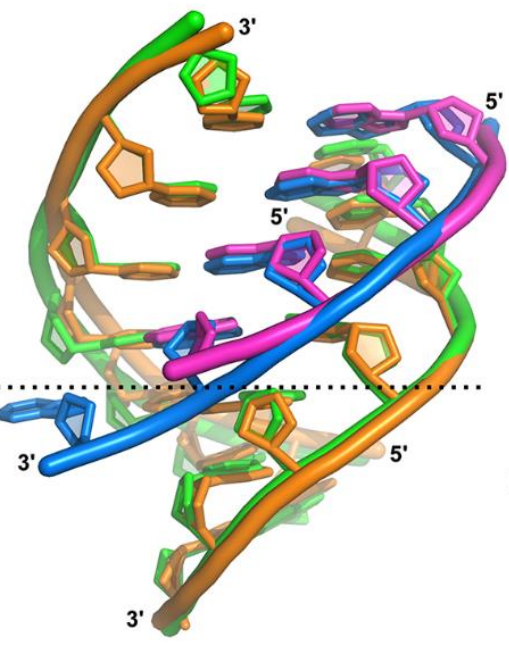

MALAT1 ENE - A-rich tract TWIFB1 upper ENE - poly(A)

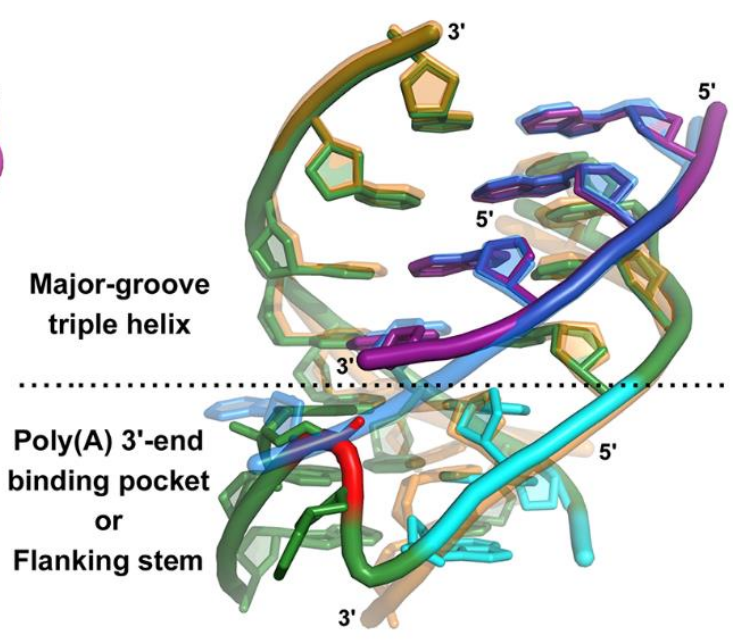

TWIFB1 lower ENE - poly(A) TWIFB1 upper ENE - poly(A)
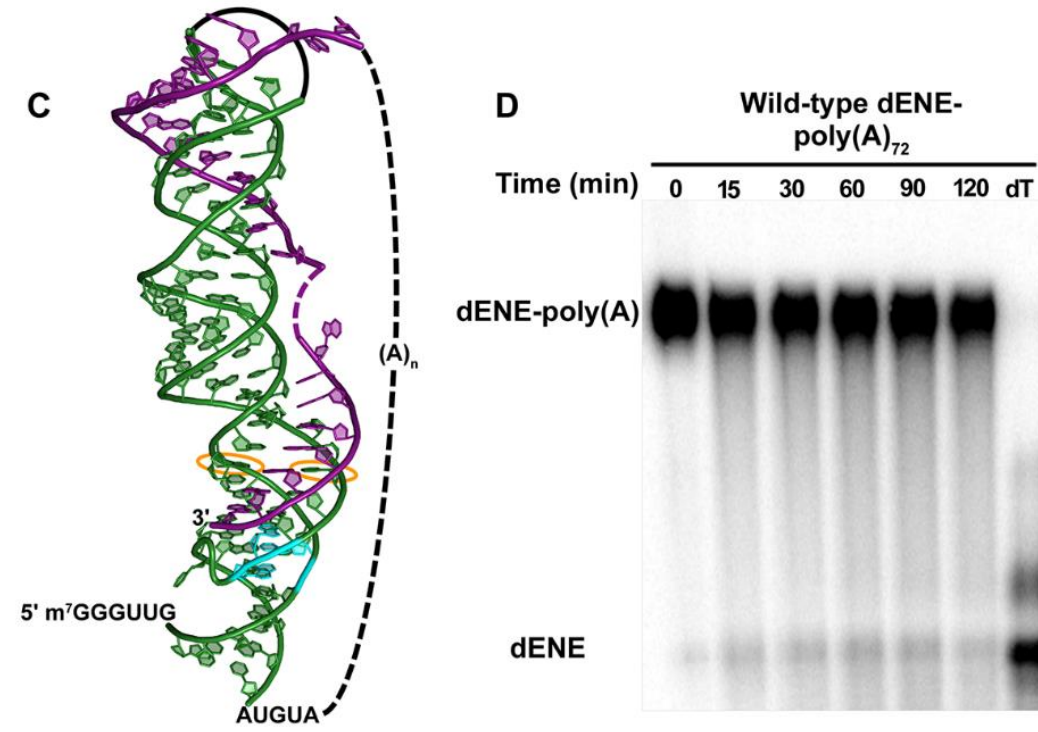

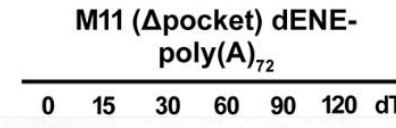

\begin{tabular}{lllllll}
\multicolumn{6}{c}{$\begin{array}{c}\text { M26 (double-mutant) dENE- } \\
\text { poly }(A)_{69} G(A)_{22}\end{array}$} \\
\hline 0 & 15 & 30 & 60 & 90 & 120 & dT
\end{tabular}

dENE-poly(A)

dENE 

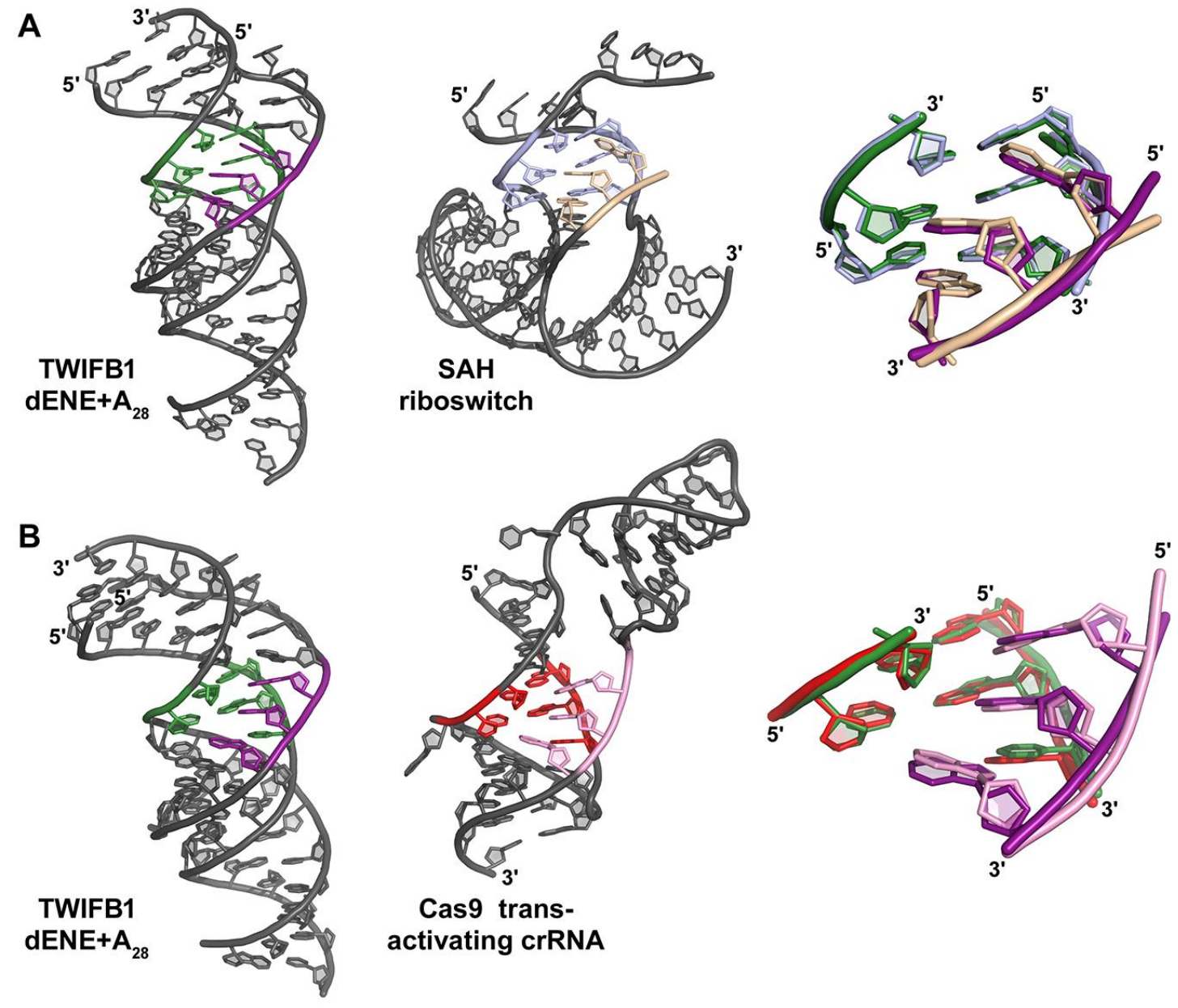
Cas9 trans-
activating crRNA
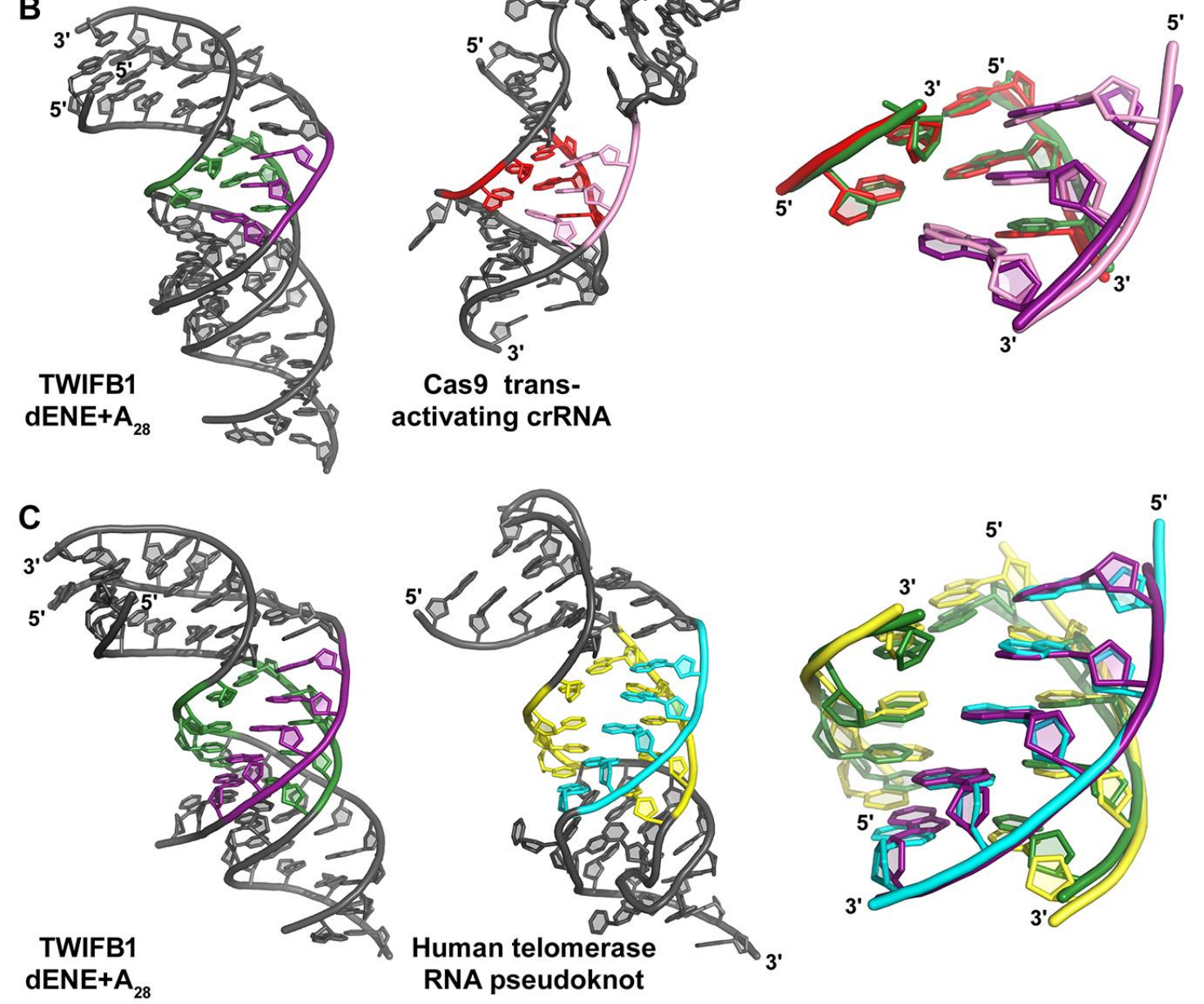

Fig. 6. Similarity between structural motifs identified in the dENE+poly $(A)_{28}$ complex and equivalent motifs from other RNAs. Only the motifs that are common between compared structures are highlighted in color. (A) Structures of the dENE+poly $(\mathrm{A})_{28}$, the SAH riboswitch (PDB 3NPQ (20)) and superposition of their WC/H A-minor motifs (only interactions involving A7-A9 from the dENE) with an RMSD $=0.9 \AA$. (B) Structures of the dENE+poly $(A)_{28}$, the Cas9 trans-activating crRNA (PDB 5X2G (21)) and superposition of their WC/H A-minor interaction and quintuple-base transition motif (only interactions involving A8-A10 from the dENE) with RMSD = $0.9 \AA$. (C) Structures of the dENE+poly $(A)_{28}$, the hTR pseudoknot (PDB 2 K95 (22)) and superposition of their quintuple-base transition motif and major-groove triplexes (only interactions involving A9-A13 from the dENE) with $\mathrm{RMSD}=1.5 \AA$. 